\title{
Evaluation of mRNA Expression Levels of cyp51A and $m d r 1$, Candidate Genes for Voriconazole Resistance in Aspergillus flavus
}

\author{
Azam Fattahi, ${ }^{1}$ Farideh Zaini, ${ }^{1}$ Parivash Kordbacheh, Sasan Rezaie, ${ }^{1}$ Mahin Safara, ${ }^{1}$ Roohollah \\ Fateh, ${ }^{2}$ Shirin Farahyar, ${ }^{3}$ Ali Kanani, and Mansour Heidari ${ }^{4,5,}$ \\ ${ }^{1}$ Department of Medical Mycology and Parasitology, School of Public Health, Tehran University of Medical Sciences, Tehran, IR Iran \\ ${ }_{3}^{2}$ Department of Microbiology and Immunology, Faculty of Medicine, Qom University of Medical Sciences, Qom, IR Iran \\ ${ }_{3}^{3}$ Department of Medical Mycology and Parasitology, Faculty of Medicine, Iran University of Medical Sciences, Tehran, IR Iran \\ ${ }_{5}^{4}$ Department of Medical Genetics, Tehran University of Medical Sciences, Tehran, IR Iran \\ 5 Exprerimental Medicine Research Center, Tehran University of Medical Sciences, Tehran, IR Iran \\ ${ }^{*}$ Exprerimental Medicine Research Center, Tehran University of Medical Sciences, Tehran, IR Iran \\ mheidari@sina.tums.ac.ir \\ Received 2015 February 6; Revised 2015 May 11; Accepted 2015 May 24.
}

\begin{abstract}
Background: Voriconazole Resistance (VRC-R) in Aspergillus flavus isolates impacts the management of aspergillosis, since azoles are the first choice for prophylaxis and therapy. However, to the best of our knowledge, the mechanisms underlying voriconazole resistance are poorly understood.

Objectives: The present study was designed to evaluate mRNA expression levels of cyp51A and $m d r 1$ genes in voriconazole resistant $A$. flavus by a Real-Time Reverse Transcriptase Polymerase Chain Reaction (RT-PCR) technique.

Materials and Methods: Five A. flavus isolates with resistance to VRC were examined by a RT-PCR approach.

Results: Four out of five isolates revealed cyp51A and $m d r 1$ mRNA overexpression. Interestingly, the isolate, which was negative for cyp51A and $m d r 1$ mRNA expression showed a high voriconazole Minimum Inhibitory Concentration (MIC). Furthermore, a computational-based analysis predicted that voriconazole resistance could be mediated through cooperation with a network protein interaction.

Conclusions: Our experimental and in silico findings may provide new insight in the complex molecular pathways of drug resistance and also could assist design an efficient therapeutic strategy for aspergillosis treatment.
\end{abstract}

Keywords: Drug Resistance, Minimum Inhibitory Concentration, cyp51A, $m d r 1$

\section{Background}

Invasive Aspergillosis (IA) is widespread in immunocompromised individuals and has become a great concern for the management of such patients $(1,2)$. Although Aspergillus fumigatus is responsible for the majority of IA, emerging epidemiological reports have suggested an increase in the frequency of non-fumigatus isolates including $A$. flavus (3-7). Aspergillus flavus is the second most common Aspergillus spp. causing IA $(2,8)$. Until now, therapy for IA has been limited to azoles, echinocandins and polyenes. The use of voriconazole has improved the treatment of invasive aspergillosis. Voriconazole blocks ergosterol biosynthesis by inhibiting the activity of $14-\alpha$-lanosterol demethylase (CYP51A1), a cytochrome P450 enzyme involved in the conversion of lanosterol to 4,4-dimethylcholesta-8 (9),14,24-trien-3ß-ol $(9,10)$. Voriconazole-resistant A. flavus was originally identified in a patient with IA, underlying a lung surgical operation (11). Recently, increasing Voriconazole Resistance (VRC-R) in clinical isolates of Aspergillus spp. has been reported worldwide $(2,11)$.

Based on limited studies, the most obvious mechanism of VRC-R in A. flavus involves overexpression or mutations of cyp51A $(11,12)$. Several studies have suggested that multiple mechanisms unrelated to cyp51A undoubtedly exist. Furthermore, various studies from years 2006 to 2009 failed to detect genetic alterations within the cyp $51 \mathrm{~A}$ coding sequence in $40 \%$ of triazole resistant Aspergillus spp. (1, 13-15). The primary mechanism responsible for azole resistance in clinical Candida isolates is overexpression of Multidrug Resistance Efflux Pumps (MDR-EPs) (16, 17); upregulation of genes encoding MDR-EPs, contributing to triazole resistance in A. flavus have been previously described (18, 19). Two major classes of efflux proteins, the ATP-Binding Cassette (ABC) pumps and the Major Facilitator Superfamily (MFS) transporters have been shown to contribute to drug resistance (20-23).

\section{Objectives}

The present study was designed to evaluate the mRNA expression levels of cyp51A and mdr1 genes in voricon-

Copyright (C) 2015, Ahvaz Jundishapur University of Medical Sciences. This is an open-access article distributed under the terms of the Creative Commons Attribution-NonCommercial 4.0 International License (http://creativecommons.org/licenses/by-nc/4.0/) which permits copy and redistribute the material just in noncommercial usages, provided the original work is properly cited. 
Fattahi A et al.

azole resistant A. flavus by a Real-Time Reverse Transcriptase-Polymerase Chain Reaction approach.

\section{Materials and Methods}

\subsection{Sampling and Susceptibility Testing}

Forty-five A. flavus archived strains isolated by a previous study were obtained from the Medical Mycology Laboratory, School of Public Health, Tehran University of Medical Sciences from January 2004 to December 2006. The Clinical and Laboratory Standards Institute (CLSI) M38-A3 microdilution method was used for assessment of the susceptibility of A. flavus strains to voriconazole (Ankleshwar [Gujarat], India). Candida krusei ATCC 6258 was used as a control strain for each plate $(24,25)$. All isolates were cultured on potato dextrose agar (Merck, Germany) at $35^{\circ} \mathrm{C}$ for seven days. Fresh conidial suspensions were collected and counted by hemocytometer; and the cell density was adjusted to $0.4-2.5 \times 10^{4} \mathrm{CFU}$ $\mathrm{mL}$. Antifungal susceptibility testing was performed and Minimum Inhibitory Concentrations (MICs) were determined after 48 hours.

\subsection{RNA Extraction and cDNA Synthesis}

Strains of A. flavus that demonstrated resistance to VRC as well as sensitive strains were selected for RNA extraction. Conidia from each strain was inoculated in liquid culture (Merck, Germany) and incubated at $30^{\circ} \mathrm{C}$ with constant shaking at $120 \mathrm{rpm}$ for 20 - 24 hours. Subsequently, mycelia were collected at log-phase by filtration and washing thoroughly with sterile water. They were then frozen quickly in liquid nitrogen, and cell wall disrupted by pestle. Total RNA was extracted using the RNXPlus Kit (Sinaclon, Iran). The quantity and quality of RNA were analyzed using nanodrop (ND-1000, Thermo Scientific Fisher, US). To avoid any genomic contamination, RNA was treated with DNase1 (Qiagen, Hilden, Germany), according to the manufacturer's instructions. Treatment of total RNA with DNase1 improves the reliability of the quantitative method, considerably (26).

cDNA synthesis was performed as previously described with some modifications $(27,28)$. Briefly, single stranded cDNA (sscDNA) was synthesized using $6 \mu \mathrm{g}$ RNA, $20 \mathrm{pmol} / \mu \mathrm{L}$ random hexamer (Fermentas, Burlington, Canada), $20 \mathrm{pmol} / \mu \mathrm{L}$ oligodT (Fermentas, Burlington, Canada) and $10 \mathrm{mM}$ of dNTP mix (Fermentas, Burlington, Canada), then incubated at $65^{\circ} \mathrm{C}$ for ten minutes followed by addition of $20 \mathrm{U}$ Ribolock (Fermentas, Burlington, Canada), $7.5 \mu \mathrm{L}$ of $5 \mathrm{X}$ Reverse Transcriptase (RT) buffer (Fermentas, Burlington, Canada) and 200 U Moloney Murine Leukemia Virus (M-MuLV) reverse transcriptase enzyme(Fermentas, Burlington, Canada) and then incubated at $70^{\circ} \mathrm{C}$ for 10 minutes followed by incubation at $42^{\circ} \mathrm{C}$ for 60 minutes. cDNA was checked with $ß$ tubulin (tubF $5^{\prime}$-GATG GCTGCTTCTGACTTCC-3', tubR 5'-GGTCGTTCATGTTGCTCTCA-3') primers (designed by the Primer 3 online software version 0.4.0 and synthesized by the Bioneer company, Korea) as part of housekeeping with the following PCR conditions: five min at $94^{\circ} \mathrm{C} ; 30$ cycles of 30 seconds at $94^{\circ} \mathrm{C}, 30$ seconds at $55^{\circ} \mathrm{C}, 45$ seconds at $72^{\circ} \mathrm{C}$, and seven minutes at $72^{\circ} \mathrm{C}$.

\subsection{Real-Time Reverse Transcriptase-Polymerase Chain Reaction}

Real-time Reverse Transcriptase-PCR (RT-PCR) was carried out to determine the differences in expression patterns of identified genes between resistant and sensitive A. flavus isolates, using a CFX96 ${ }^{\mathrm{TM}}$ Real-Time System (C1000TM Thermal Cycler) (Qiagen/Corbett Rotor-Gene $6000)$. In order to analyze the expression of cyp51A and mdr1 for voriconazole resistance in A. flavus, specific primers (Table 1) corresponding to the coding regions of cyp51A and $m d r 1$ genes were designed by the Primer 3 online software version 0.4.0 (synthesized by Bioneer Korea). After cDNA synthesis, real-time RT-PCR was performed in $20 \mu \mathrm{L}$ reactions containing $1 \mu \mathrm{L}$ cDNA target, $100 \mathrm{Nm}$ forward and reverse primers and 1x SYBR Premix Ex Taq ${ }^{\mathrm{TM}}$ (Takara, Tokyo, Japan). Experiments were conducted in triplicates. The PCR conditions were as follows: activation at $95^{\circ} \mathrm{C}$ for 30 seconds, amplification at $95^{\circ} \mathrm{C}$ for 5 seconds, $60^{\circ} \mathrm{C}$ for 30 seconds during 40 cycles. The relative value of the expression level of each gene was calculated by comparing the Cycle Thresholds (CTs) of the target genes with that of housekeeping genes (tub) using the $2^{-\Delta \Delta c t}$ method, as previously described (29).

\subsection{In Silico Study}

In order to analyze the Protein-Protein Interactions (PPI) the Search Tool for the Retrieval of Interacting Genes/Proteins (STRING) database version 9.1 (http://stringdb. org/) was used. The predicted networks relied on physical and functional interactions of A. flavus.

\section{Results}

\subsection{Drug Susceptibility of Aspergillus flavus}

Five out of $45 \mathrm{~A}$. flavus tested isolates, according to the proposed interpretative breakpoints (24) with high MIC values in the presence of voriconazole, were defined as VRC resistant (Table 2).Three isolates, No 3, 4 and 5 were found to display the highest level of VRC-R(MIC, $16 \mu \mathrm{g} / \mathrm{ml}$ ), whereas isolates 1 and 2 showed low levels of resistance. To verify the development of voriconazole resistance in the isolates, they were cultured on Sabouraud (SDA) agar containing progressively increasing concentrations of voriconazole ( 0.5 to $50 \mu \mathrm{g} / \mathrm{mL}$ ).

\subsection{Cyp51A and mdr1 Expression in Aspergillus flavus}

Five VRC resistant of A. flavus were selected for qRT-PCR experiments to study mRNA expression of the cyp51A 
Fattahi A et al.

and $m d r 1$, a significant overexpression of cyp51A was found in four isolates (6.89 to 7.93 folds) ( $\log _{2} \mathrm{P}<0.001$ ) (Figure 1), whereas there was no significant expression of these gene in one.

A variable expression of the mdr1 mRNA was detected in four samples. Moderate and high levels of mdr1 mRNA was observed in isolate number 1 (4.77) and isolates number 2, 3 and 4 (10.94, 11.09 and 18.12 fold, respectively) ( $\left.\log ^{2} \mathrm{P}<0.001\right)$.In contrast, isolate number 5 at the highest MIC, did not express mdr1 and cyp51A.

\subsection{Predicting Protein Interactions in Aspergillus flavus}

To determine which protein partners are implicated in the mechanism of A. flavus drug resistance by cyp $51 A$ and $m d r 1$, we used the STRING database, as described in the materials and methods section. As shown in Figure 2, several important proteins were potentially associated with the expressed genes obtained from the realtime PCR.

\begin{tabular}{lcc}
\hline Table 1. Primer Sequences Used in This Study & \\
\hline Primer & Sequence & $\begin{array}{c}\text { PCR Product } \\
\text { Size, bp }\end{array}$ \\
\hline CYP51AF & 5'-ATGTCAATGCCGAGGAGAT-3' & 198 \\
& 5'-AAGTTGGGGGATGTCTTGA-3' & \\
MDR1F & 5'-CTTTCCTGTCCACCGAGAC-3' & 178 \\
& 5'-GAAGTACCCACAAGCCAGA-3' & \\
\hline
\end{tabular}

Table 2. In Vitro Susceptibility of Laboratory VoriconazoleResistant Aspergillus flavus Isolates ${ }^{\mathrm{a}, \mathrm{b}}$

\begin{tabular}{|c|c|}
\hline Isolate No. & MIC, $\mu \mathrm{g} / \mathrm{mL}$ of VCZ \\
\hline Afl-VCZ1 & 2 \\
\hline Afl-VCZ2 & 4 \\
\hline Afl-VCZ3 & 16 \\
\hline Afl-VCZ4 & 16 \\
\hline Afl-VCZ5 & 16 \\
\hline
\end{tabular}

Figure 1. Assessment of mRNA Expression Levels of cyp51A and mdr1 genes

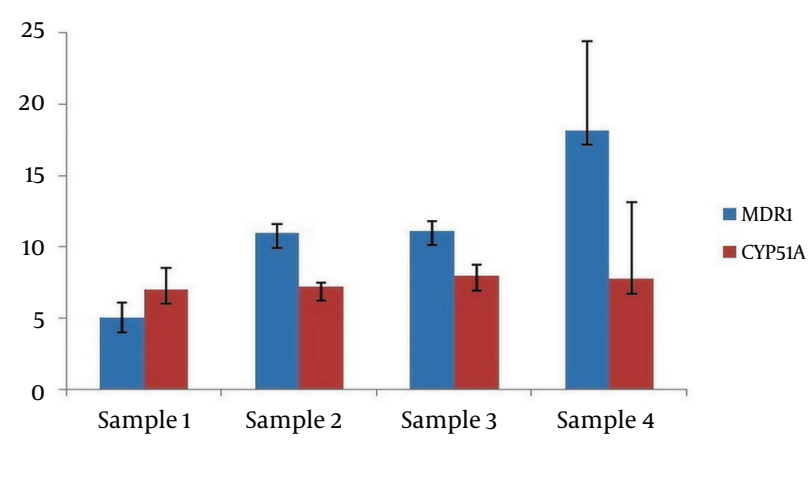

Figure 2. Protein Interaction Network Prediction by STRING

A

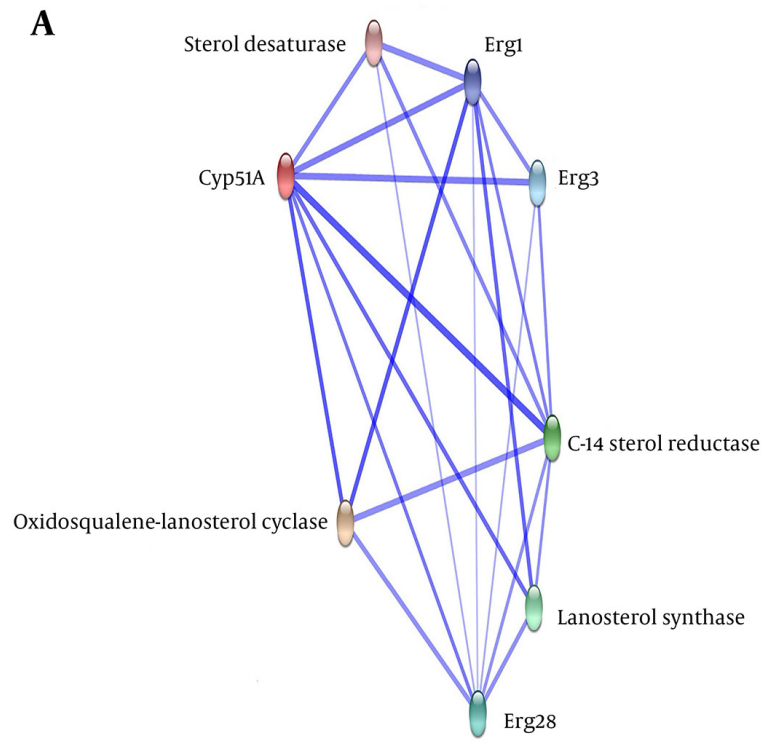

B

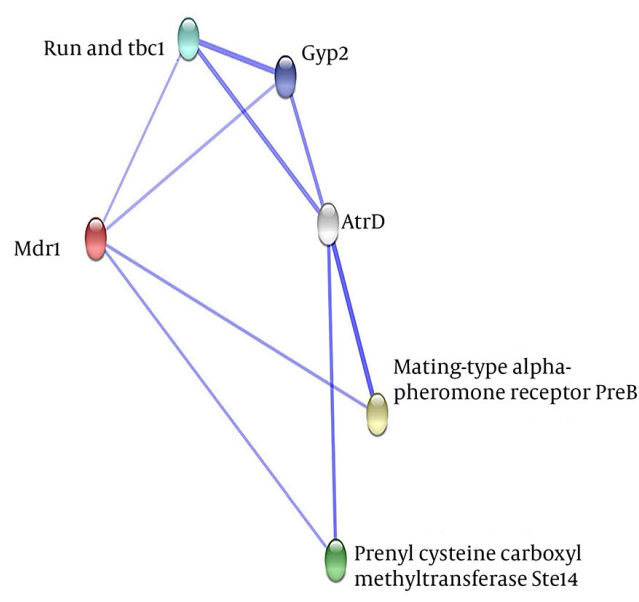

The potential biological functions of the encoded proteins by cyp51A and $m d r 1$ showed their possible role, which could depend on their interactions with a network of other cellular proteins. A, The highest-scoring interaction partners of cyp51A. As the confidence scores for these interactions are very high, more specific protein partners are shown. B, The interaction network of $m d r 1$ display several protein partners. 
Fattahi A et al.

\section{Discussion}

In the present study, we evaluated mRNA expression levels of cyp51A and $m d r 1$ genes, in five A. flavus isolates. Both genes seemed to contribute to the development of drug resistance in the four resistant isolates. So far, different mechanisms have been reported for the resistance to azoles in A. flavus including genetic changes and/or overexpression of cyp51A, cyp51B and cyp51C as well as decreases in the concentration of intracellular drugs. The latter mechanism could be a consequence of either overexpression of efflux pumps or due to reduction in drug penetration $(2,11,18,19)$. The patterns of voriconazole resistance appear to differ in different cases. Various studies have demonstrated that point mutations in the cyp51A gene encoding 14-sterol demethylase could be a major mechanism accounting for triazole resistance in Aspergillus spp. $(14,30,31)$. However, it has been shown that $40-70 \%$ of VRC-RA. flavus failed to demonstrate cyp51 mutations (19).

Over the past decade, extensive studies attempted to overcome $m d r$, as one of the major challenges in drug resistance of fungi. Moreover, it is now clear that overexpression of $m d r 1$ has critical functions in human cancer treatment by reduction of the uptake and increasing the efflux of anti-cancer drugs (19). Our data demonstrated, a significant up regulation of cyp51A (6.89 to 7.93 folds) $(\mathrm{P}<$ $0.001)$ in four isolates, yetisolate number 5 , at the highest MIC, did not express cyp51A and $m d r 1$. It has been suggested that up regulation in azole target enzyme gene cyp $51 A$ is associated with azole resistance in A. fumigatus and $A$. lentulus $(10,32)$. In contrary to these reports, Liu et al. indicated that the expression levels of the azole target enzyme genes cyp51A, cyp51B and cyp51C were not associated with VRC resistance in A. flavus (2). However, their results are in disagreement with our findings (2).

The lack of data showing an association between ABC or MFS multidrug efflux pumps and triazole resistance in Aspergillus, encouraged us to identify candidate efflux pumps that could be associated with azole resistance in A. flavus. In this regard, our data indicated significant differences in expression level of $m d r 1$ between resistant and sensitive isolates. Moderate and high levels of $m d r 1$ mRNA in four isolates mirrored MIC results with the exception of the fifth isolate, which exhibited no expression of mdr1 mRNA. Our results are in agreement with the report of Krishnan-Natesan et al. (11), which showed degrees of MDR-EPs over expression in all VRC-R isolates of A. flavus; the level of MDR- EPs correlated with the degree of resistance as reflected by the MICs of the drugs. They also showed that there were no alterations in the cyp $51 \mathrm{~A}$ as well as MDR-EPs overexpression in some isolates.

Co-regulation (co-expression and co-silencing) of $m d r 1$ and cyp1A was reported in various human malignancies. Lampen et al. determined the co-induction of $m d r 1$ and cyp1 genes in human Caco-2 intestinal cells on treatment with carcinogenic aromatic hydrocarbons (33). Finally, an in silico study was performed using the online STRING program; in order to estimate the potential biological processes of genes that act in ergosterol biosynthesis and efflux pumps (EPs) function. Studies have shown that the majority of biological processes are regulated through association of protein molecules. In addition, functional units of cells are often complex assemblies of several macromolecules, where proteins play a vital role. Therefore, protein-protein interaction networks play an important role in the organization of an organism's life.

At the highest confidence score, erg1, erg3 and erg28 Lanosterol synthase proteins were predicted to interact either directly or indirectly with the cyp51A (erg11) protein. Furthermore, Erg1 catalyzes the first oxygenation step in sterol biosynthesis and is suggested to be one of the rate-limiting enzymes in this pathway. The interaction of erg1 seems to be crucial for sterol biosynthesis. As shown in Figure 2, ABC a-pheromone efflux pump atrD, is directly or indirectly potentially associated with the $m d r 1$. Furthermore, atrD as the efflux protein removes drug accumulated in the cell with the expense of energy and reduces the concentration of drug required for the inhibition of growth. The in silico results predicted that voriconazole resistance could be mediated through cooperation of protein partners interaction. Taken together, our experimental and in silico findings may provide new insight into the complex molecular pathways in drug resistance and could assist design an efficient therapeutic strategy for aspergillosis.

Our data suggested that there are different scenarios that explain the biological significance of the expression of $m d r 1$ and cyp51A in drug resistance, at least for our limited samples. There are two hypotheses: 1) Mdr1 protein regulates cyp51A mRNA expression via a positive dominant effect. This hypothesis comes from our findings, which showed that in the absence of $m d r 1$, we could not detect cyp51A mRNA expression. The lack of $m d r 1$ expression could have occurred due to gene deletion or other genetic and epigenetic phenomena. 2) Several unknown genes, loci and molecular pathways could play central roles in the development of drug resistance, which is known as a complex trait. Consequently, it is quite understandable that in the absence of cyp51A and $m d r 1$ in isolate number 5 , the aforementioned mechanisms might have been implicated in the drug resistance. Collectively, the above observations suggest that cyp51A and $m d r 1$, other genes and loci are responsible for voriconazole resistance in A.flavus. These data suggested that more investigation should be done on larger samples.

\section{Acknowledgments}

The authors would like to express their gratitude to Dr. Hossein Mirhendi, Mrs. Fatemeh Karami, Mrs. Mandana Afshar Pad and Dr. Hoda Abedkhojasteh for their kind cooperation. The Authors acknowledge the Vice Chancellor for Research at the Tehran University of Medical Sciences and Health for their financial support. This research was 
Fattahi A et al.

supported by the Tehran University of Medical Sciences and Health Services (grant number 23864).

\section{Footnotes}

Authors' Contribution:Azam Fattahi, Mansour Heidari, and Farideh Zaini: contributed to concept and study design, analysis of data, and supervision of sections of the study; Azam Fattahi and Roohollah Fateh: carried out molecular and susceptibility testing of antifungal drugs experimentation; Azam Fattahi and Roohollah Fateh were responsible for the molecular studies, sequence alignment, and analysis of the data; Ali Kanani was assisted with molecular genetics; Shirin Farahyar, Parivash Kordbacheh, Sasan Rezaie and Mahin Safara: provided scientific advice; Azam Fattahi prepared the manuscript which Mansour Heidari and Farideh Zaini critically revised. All authors read and approved the final manuscript.

Funding/Support:This research was supported by the Tehran University of Medical Sciences and Health Services (grant number 23864).

\section{References}

1. Denning DW, Perlin DS. Azole resistance in Aspergillus: a growing public health menace. Future Microbiol. 2011;6(11):1229-32. doi: 10.2217/fmb.11.118. [PubMed: 22082283]

2. Liu W, Sun Y, Chen W, Liu W, Wan Z, Bu D, et al. The T788G mutation in the cyp51C gene confers voriconazole resistance in Aspergillus flavus causing aspergillosis. Antimicrob Agents Chemother. 2012;56(5):2598-603. doi:10.1128/AAC.05477-11. [PubMed: 22314539]

3. Bille J, Marchetti O, Calandra T. Changing face of health-care associated fungal infections. Curr Opin Infect Dis. 2005;18(4):314-9. [PubMed: 15985827]

4. Chakrabarti A, Singh R. The emerging epidemiology of mould infections in developing countries. Curr Opin Infect Dis. 2011;24(6):521-6. doi: 10.1097/QCO.0b013e32834ab21e. [PubMed: 21799406]

5. Lopez-Cortes LE, Garcia-Vidal C, Ayats J, Gudiol C, Bodro M, Sanchez-Ortega I, et al. [Invasive aspergillosis with extrapulmonary involvement: pathogenesis, clinical characteristics and prognosis]. Rev Iberoam Micol. 2012;29(3):139-43. doi: 10.1016/j. riam.2011.10.001. [PubMed:22108606]

6. Malani AN, Kauffman CA. Changing epidemiology of rare mould infections: implications for therapy. Drugs. 2007;67(13):1803-12. [PubMed: 17722951]

7. Van Der Linden JW, Warris A, Verweij PE. Aspergillus species intrinsically resistant to antifungal agents. Med Mycol. 2011;49 Suppl 1:S82-9. doi: 10.3109/13693786.2010.499916. [PubMed: 20662634]

8. Chen CY, Sheng WH, Cheng A, Chen YC, Tsay W, Tang JL, et al. Invasive fungal sinusitis in patients with hematological malignancy: 15 years experience in a single university hospital in Taiwan. BMC Infect Dis. 2011;11:250. doi:10.1186/1471-2334-11-250. [PubMed: 21939544]

9. Ferreira ME, Colombo AL, Paulsen I, Ren Q, Wortman J, Huang J, et al. The ergosterol biosynthesis pathway, transporter genes, and azole resistance in Aspergillus fumigatus. Med Mycol. 2005;43 Suppl 1:S313-9. [PubMed:16110826]

10. Howard SJ, Pasqualotto AC, Denning DW. Azole resistance in allergic bronchopulmonary aspergillosis and Aspergillus bronchitis. Clin Microbiol Infect. 2010;16(6):683-8. doi: 10.1111/j.14690691.2009.02911.x. [PubMed:19673966]

11. Krishnan-Natesan S, Chandrasekar PH, Alangaden GJ, Manavathu EK. Molecular characterisation of cyp51A and cyp51B genes coding for P450 14alpha-lanosterol demethylases A (CYP51Ap) and B (CYP51Bp) from voriconazole-resistant laboratory isolates of Aspergillus flavus. Int J Antimicrob Agents. 2008;32(6):519-24. doi: 10.1016/j.ijantimicag.2008.06.018. [PubMed: 18775650]

12. Mann PA, Parmegiani RM, Wei SQ, Mendrick CA, Li X, Loebenberg $\mathrm{D}$, et al. Mutations in Aspergillus fumigatus resulting in reduced susceptibility to posaconazole appear to be restricted to a single amino acid in the cytochrome P450 14alpha-demethylase. Antimicrob Agents Chemother. 2003;47(2):577-81. [PubMed:12543662]

13. Howard SJ, Arendrup MC. Acquired antifungal drug resistance in Aspergillus fumigatus: epidemiology and detection. Med Mycol. 2011;49 Suppl 1:S90-5. doi: 10.3109/13693786.2010.508469. [PubMed: 20795765]

14. Howard SJ, Cerar D, Anderson MJ, Albarrag A, Fisher MC, Pasqualotto AC, et al. Frequency and evolution of Azole resistance in Aspergillus fumigatus associated with treatment failure. Emerg Infect Dis. 2009;15(7):1068-76. doi: 10.3201/eid1507.090043. [PubMed: 19624922]

15. Snelders E, Melchers WJ, Verweij PE. Azole resistance in Aspergillus fumigatus: a new challenge in the management of invasive aspergillosis? Future Microbiol. 2011;6(3):335-47. doi: 10.2217| fmb.11.4. [PubMed: 21449843]

16. Holmes AR, Lin YH, Niimi K, Lamping E, Keniya M, Niimi M, et al $\mathrm{ABC}$ transporter Cdr1p contributes more than Cdr2p does to fluconazole efflux in fluconazole-resistant Candida albicans clinical isolates. Antimicrob Agents Chemother. 2008;52(11):3851-62. doi: 10.1128/AAC.00463-08. [PubMed:18710914]

17. Rogers PD, Barker KS. Genome-wide expression profile analysis reveals coordinately regulated genes associated with stepwise acquisition of azole resistance in Candida albicans clinical isolates. Antimicrob Agents Chemother. 2003;47(4):1220-7. [PubMed: 12654650]

18. Jost KE. Characterization of ABC-Efflux Pump AflMDR2 in Voriconazole Resistant Isolates of Aspergillus flavus. USA: Kalamazoo College; 2010.

19. Natesan SK, Lamichchane AK, Swaminathan S, Wu W. Differential expression of ATP-binding cassette and/or major facilitator superfamily class efflux pumps contributes to voriconazole resistance in Aspergillus flavus. Diagn Microbiol Infect Dis. 2013;76(4):458-63. doi: 10.1016/j.diagmicrobio.2013.04.022. [PubMed: 23886435]

20. Akins RA. An update on antifungal targets and mechanisms of resistance in Candida albicans. Med Mycol. 2005;43(4):285-318. [PubMed: 16110776]

21. Del Sorbo G, Schoonbeek H, De Waard MA. Fungal transporters involved in efflux of natural toxic compounds and fungicides. Fungal Genet Biol. 2000;30(1):1-15. [PubMed:10955904]

22. Ernst R, Klemm R, Schmitt L, Kuchler K. Yeast ATP-binding cassette transporters: cellular cleaning pumps. Methods Enzymol. 2005;400:460-84. doi:10.1016/S0076-6879(05)00026-1. [PubMed: $16399365]$

23. Marger MD, Saier MH. A major superfamily of transmembrane facilitators that catalyse uniport, symport and antiport. Trends Biochem Sci. 1993;18(1):13-20. [PubMed: 8438231]

24. Wayne P. Clinical and Laboratory Standards Institute: Reference method for broth dilution antifungal susceptibility testing of yeasts; approved standard M38A3. Chicago; Clinical and Laboratory Standards InstituteWayne. 2008.

25. Wayne P. Clinical and Laboratory Standards Insititute. Reference method for broth dilution antifungal susceptibility testing of Yeast; informational supplement, M27-A3. Chicago; Clinical and Laboratory Standards Institute,Wayne. 2007.

26. Semighini CP, Marins M, Goldman MH, Goldman GH. Quantitative analysis of the relative transcript levels of $\mathrm{ABC}$ transporter Atr genes in Aspergillus nidulans by real-time reverse transcription-PCR assay. Appl Environ Microbiol. 2002;68(3):1351-7. [PubMed: 11872487]

27. Kazemi-Rad E, Mohebali M, Khadem-Erfan MB, Saffari M, Raoofian $\mathrm{R}$, Hajjaran $\mathrm{H}$, et al. Identification of antimony resistance markers in Leishmania tropica field isolates through a cDNAAFLP approach. Exp Parasitol. 2013;135(2):344-9. doi:10.1016/j.exppara.2013.07.018. [PubMed: 23928349]

28. Tavakoli M, Zaini F, Kordbacheh M, Safara M, Raoofian R, Heidari M. Upregulation of the ERG11 gene in Candida krusei by azoles. Daru. 2010;18(4):276-80. [PubMed: 22615628] 
29. Livak KJ, Schmittgen TD. Analysis of relative gene expression data using real-time quantitative PCR and the 2(-Delta Delta C(T)) Method. Methods. 2001;25(4):402-8. doi: 10.1006/meth.2001.1262. [PubMed: 11846609]

30. Howard SJ, Webster I, Moore CB, Gardiner RE, Park S, Perlin DS, et al. Multi-azole resistance in Aspergillus fumigatus. Int $J$ Antimicrob Agents. 2006;28(5):450-3. doi: 10.1016/j.ijantimicag.2006.08.017. [PubMed: 17034993]

31. Pelaez T, Gijon P, Bunsow E, Bouza E, Sanchez-Yebra W, Valerio $\mathrm{M}$, et al. Resistance to voriconazole due to a G448S substitution in Aspergillus fumigatus in a patient with cerebral aspergillo- sis. J Clin Microbiol. 2012;50(7):2531-4. doi: 10.1128/JCM.00329-12. [PubMed: 22573589]

32. Mellado E, Alcazar-Fuoli L, Cuenca-Estrella M, Rodriguez-Tudela JL. Role of Aspergillus lentulus 14-alpha sterol demethylase (Cyp51A) in azole drug susceptibility. Antimicrob Agents Chemother 2011;55(12):5459-68. doi: 10.1128/AAC.05178-11. [PubMed: 21947395]

33. Lampen A, Ebert B, Stumkat L, Jacob J, Seidel A. Induction of gene expression of xenobiotic metabolism enzymes and $\mathrm{ABC}$ transport proteins by $\mathrm{PAH}$ and a reconstituted $\mathrm{PAH}$ mixture in human Caco-2 cells. Biochim Biophys Acta. 2004;1681(1):38-46. doi: 10.1016/j.bbaexp.2004.09.010. [PubMed:15566942] 